\title{
T-cell development of resistance to apoptosis is driven by a metabolic shift in carbon source and altered activation of death pathways
}

\author{
CD Bortner ${ }^{1}$, AB Scoltock ${ }^{1}$, DW Cain ${ }^{1}$ and JA Cidlowski ${ }^{\star, 1}$
}

We developed a model system to investigate apoptotic resistance in T cells using osmotic stress (OS) to drive selection of deathresistant cells. Exposure of $S 49$ (Neo) T cells to multiple rounds of OS followed by recovery of surviving cells resulted in the selection of a population of T cells (S49 (OS 4-25)) that failed to die in response to a variety of intrinsic apoptotic stimuli including acute OS, but remained sensitive to extrinsic apoptotic initiators. Genome-wide microarray analysis comparing the S49 (OS 4-25) with the parent $\mathbf{S} 49$ (Neo) cells revealed over 8500 differentially regulated genes, with almost $90 \%$ of those identified being repressed. Surprisingly, our data revealed that apoptotic resistance is not associated with expected changes in pro- or antiapoptotic Bcl-2 family member genes. Rather, these cells lack several characteristics associated with the initial signaling or activation of the intrinsic apoptosis pathway, including failure to increase mitochondrial-derived reactive oxygen species, failure to increase intracellular calcium, failure to deplete glutathione, failure to release cytochrome $c$ from the mitochondria, along with a lack of induced caspase activity. The S49 (OS 4-25) cells exhibit metabolic characteristics indicative of the Warburg effect, and, despite numerous changes in mitochondria gene expression, the mitochondria have a normal metabolic capacity. Interestingly, the S49 (OS 4-25) cells have developed a complete dependence on glucose for survival, and glucose withdrawal results in cell death with many of the essential characteristics of apoptosis. Furthermore, we show that other dietary sugars such as galactose support the viability of the S49 (OS 4-25) cells in the absence of glucose; however, this carbon source sensitizes these cells to die. Our findings suggest that carbon substrate reprogramming for energy production in the S49 (OS 4-25) cells results in stimulusspecific recognition defects in the activation of intrinsic apoptotic pathways.

Cell Death and Differentiation (2016) 23, 889-902; doi:10.1038/cdd.2015.156; published online 11 December 2015

Cell death plays an essential function in organismal life by balancing cell proliferation to preserve the natural homeostatic physiological processes in our bodies. ${ }^{1-4}$ Apoptosis is a physiological mode of cell death that permits the removal of unwanted cells from the body at a specific time or in response to a given signal. All the molecular components cells need to carry out this cell death process are present in normal healthy cells, and require only activation for apoptosis to ensue. However, in various human disease states, including neurodegeneration, autoimmunity, and cancer, a deregulation or malfunction of this inherent program occurs and cells may develop resistance to apoptosis. 5,6

Apoptosis occurs through two main signaling pathways: an extrinsic pathway that utilizes a diversified group of cell surface death receptors; ${ }^{7-14}$ and an intrinsic pathway that utilizes various intracellular organelles to execute the programmed cell death machinery. ${ }^{15-20}$ An important and well-studied point of control for both the extrinsic and intrinsic apoptotic pathways is the $\mathrm{Bcl}-2$ family of proteins that comprise both pro- and antiapoptotic members and regulate the apoptotic program through a tightly controlled series of checks and balances. $^{21,22}$
Resistance to cell death is a common feature in many disease states that impedes both therapy and treatment. The mechanisms of resistance to apoptosis are poorly understood and can vary from cell to cell. Apoptotic resistance has been reported to result from a variety of mechanisms including overexpression of antiapoptotic proteins, inhibition of proapoptotic proteins, direct inhibition of the apoptotic machinery, ${ }^{23,24}$ and cell volume regulation. ${ }^{25,26}$ As nutrient, oxygen, and energy supplies have a critical role in signaling a cell to live or die, recently it has been recognized that cross talk between cell metabolism and cell death machinery may have a major contribution in cellular life and death decisions. ${ }^{27}$

Most apoptotic stimuli result in a very asynchronous cell death, with cells dying over a period of hours to even days. In contrast, $\mathrm{T}$ cells induced to die by hyperosmotic stress undergo a rapid and synchronous apoptotic response, with over $90 \%$ of the cells dead by $4 \mathrm{~h} .{ }^{28}$ Using this system as a cell death model, we developed $T$ cells resistant to osmotic stress (OS). These S49 (OS 4-25) cells are similarly resistant to various intrinsic apoptotic stimuli, lack the initial signaling associated with programmed cell death, but remain sensitive to extrinsic apoptotic stimuli. Our analysis shows the

\footnotetext{
${ }^{1}$ Signal Transduction Laboratory, National Institute of Environmental Health Sciences, National Institutes of Health, Department of Health and Human Services, Research Triangle Park, NC, USA

${ }^{*}$ Corresponding author: JA Cidlowski, Signal Transduction Laboratory, National Institute of Environmental Health Sciences, National Institutes of Health, Department of Health and Human Services, 111 T. W. Alexander Drive, Research Triangle Park, NC 27709, USA, Tel: +919 541 1594; Fax: +919 541 1367; E-mail: cidlowski@ niehs.nih.gov Abbreviations: RVI, regulatory volume increase; MCV, mean cell volume; IPA, Ingenuity Pathway Analysis; ROS, reactive oxygen species; OCR, oxygen consumption rate; ECAR, extracellular acidification rate; PI, propidium iodide

Received 15.6.15; revised 15.10.15; accepted 22.10.15; Edited by DR Green; published online 11.12.15
} 
resistance to apoptosis can be associated with major changes in the gene expression profile and altered cell death signaling not related to changes in the $\mathrm{Bcl}-2$ family of proteins. Interestingly, the S49 (OS 4-25) cells exhibit essential signs of the Warburg effect and are completely dependent on glucose as a carbon source. Glucose withdrawal leads to cell death with multiple characteristics of apoptosis. Moreover, we show that a change in carbon substrate utilization is critical for resistance to cell death and can sensitize cells to apoptosis.

\section{Results}

Generation and characterization of osmotic-stressresistant S49 (OS 4-25) cells. S49 (Neo) cells are exceptionally sensitive to programmed cell death induced with a variety of agents. ${ }^{28}$ We exploited this property of S49 (Neo) cells by exposing them to multiple rounds of hyperosmotic stress and recovery to select cells that were resistant to apoptosis. After 25 generations of 4-h hyperosmotic treatment ( 500 mOsm mannitol) followed by several days/weeks of recovery of the viable population of cells, we developed a cell line designated S49 (OS 4-25). Microscopic examination of the S49 (OS 4-25) cells showed they were inherently larger in cell size (Figure 1a), and more than doubled their cell volume when compared with the S49 (Neo) cells (Figure 1b). The S49 (OS 4-25) cells were resistant to acute OS (Figure 1c), and gained an inherent regulatory volume increase (RVI) response under hyperosmotic conditions (Figure 1d). Remarkably, these cells were also resistant to a variety of intrinsic apoptotic stimuli, as illustrated by dexamethasone (Figure 1e) and other apoptotic agents (Supplementary Figure 1). However, they remain sensitive to extrinsic apoptotic stimuli such as Fas ligand (Figure 1f).

\section{Genome-wide microarray analysis to define apoptotic} resistance genes. Apoptotic resistance is often associated with over- or underexpression of anti- or proapoptotic genes, respectively. We examined whether changes in the gene expression were associated with intrinsic apoptotic resistance by performing a genome-wide microarray analysis. Comparing S49 (OS 4-25) cells with the parental S49 (Neo) cells showed 8560 genes being differentially expressed; 7605 $(89 \%)$ genes had a decrease in expression, whereas only $955(11 \%)$ genes were increased (Figure 2a). Supplementary Tables 1 and 2 show the top 100 genes with increased or decreased expression, respectively. We verified several genes that were differentially expressed in the microarray via real time PCR (RT-PCR) analysis (Supplementary Figure 2). Many of the genes with increased expression, including granzyme B (GZMB), ${ }^{29}$ a calcium binding protein (S100A6), ${ }^{30}$ a gap junction protein (GJA1), ${ }^{31}$ and a cyclin-dependent kinase inhibitor (CDKN2A), ${ }^{32}$ have been reported to have a role in cell death and/or apoptosis. Several genes showing decreased expression, including the inhibitory receptor of peripheral mononuclear cells (LAIR1), ${ }^{33}$ a conserved cysteine-rich protein (PLAC8), ${ }^{34}$ an apoptosis-associated speck-like protein (PYCARD), ${ }^{35}$ and a receptor tyrosine kinase (ERBB3), ${ }^{36}$ have also been reported to have a role in cell death. CARD11, a caspase recruitment domain-containing protein, has decreased expression and been reported to interact with the proapoptotic BCL10 protein. $^{37}$

Ingenuity pathway analysis (IPA) was employed to examine this gene set in regard to molecular and cellular functions. Table 1 shows the top 10 molecular and cellular functions (based on their $P$-value), along with the number of genes altered for each condition. The S49 (OS 4-25) cells showed many changes related to posttranscriptional and/or posttranslational modifications, gene expression, cell growth, and proliferation, along with cell death and survival. Network analysis using IPA showed of the 36 genes specific for the canonical apoptotic pathway, 29 genes had reduced expression in the S49 (OS 4-25) cells, whereas only 7 genes had increased expression (Figure 2b, Table 2), suggesting a global repression of the cell death response. Intriguingly, of the seven apoptotic genes with increased mRNA expression, five genes (lamin A, Fas receptor, NFkB, MRAS, and KRAS) can be considered proapoptotic in nature, despite the stimulusspecific resistance to cell death in the S49 (OS 4-25) cells.

Analysis of mRNA and protein expression of Bcl-2 family members. We analyzed various members of the Bcl-2 family for their gene and/or protein expression in the S49 (Neo) and S49 (OS 4-25) cells. Antiapoptotic family members $\mathrm{Bcl} 2 \mathrm{~L} 1$ (also known as $\mathrm{Bcl}-\mathrm{xL}$ ) and $\mathrm{Bcl}-2$ showed reduced expression via rtPCR in the S49 (OS 4-25) cells, despite the microarray suggesting that $\mathrm{Bcl}-2$ might have increased expression (Figure 3a, top). We examined the protein expression of these genes and observed no significant difference in protein expression between the $\mathrm{S} 49$ ( $\mathrm{Neo}$ ) and S49 (OS 4-25) cells (Figure 3a, bottom), suggesting the observed apoptotic resistance does not reflect overexpression of these antiapoptotic genes. In addition, we examined several proapoptotic Bcl-2 family members including Bax, Bad, and Bid for changes in gene or protein expression. Figure $3 \mathrm{~b}$ showed that none of these proapoptotic family members had a significant change in either gene or protein expression. Furthermore, other Bcl-2 family members including Bim, PUMA, Mcl-1, and NOXA showed no significant change in gene expression between the two cell lines (Figure 3c). Our results suggest that the stimulus-specific resistance to apoptosis in the S49 (OS 4-25) cells occurs independent of significant changes in either pro- or antiapoptotic Bcl-2 family members.

S49 (OS 4-25) T cells lack activation mechanisms associated with apoptosis. To analyze the molecular basis for this apoptotic resistance in S49 (OS 4-25) cells, we evaluated these cells for well-known components of the apoptotic process. Figure 4 shows that S49 (Neo) cells treated with $O S$ resulted in an increase in mitochondriaderived reactive oxygen species (ROS; a), an increase in intracellular calcium (b), a loss of glutathione (c), caspase activity (d), and release cytochrome $c(e)$, all well-recognized characteristics of cells undergoing apoptosis. In contrast, S49 (OS 4-25) cells did not show any of these apoptoticassociated changes in regards to OS. The role of reactive oxygen species and caspases in the cell death process was further examined using the ROS scavenger $\mathrm{N}$-acetylcysteine (NAC) and the pan-caspase inhibitor (Q-VD-OPh). A 


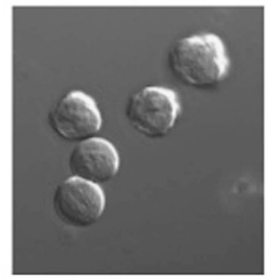

S49 (Neo)

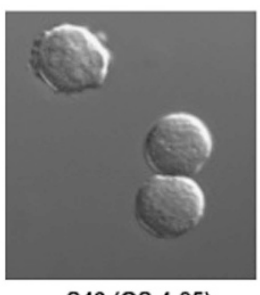

S49 (OS 4-25) b

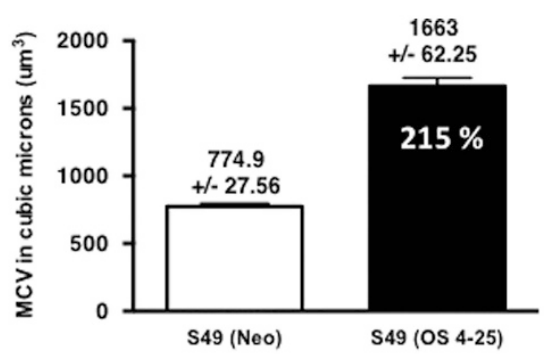

c
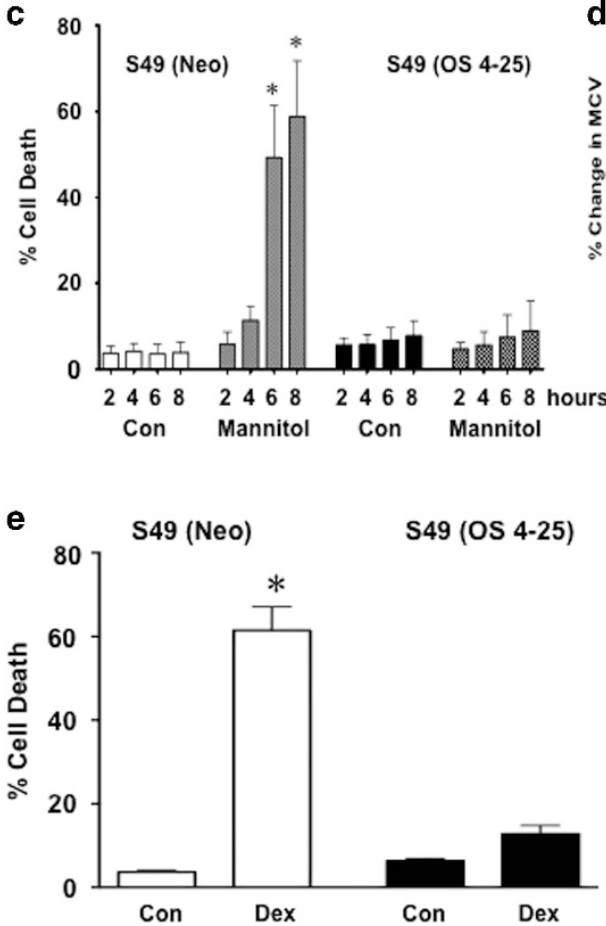

d
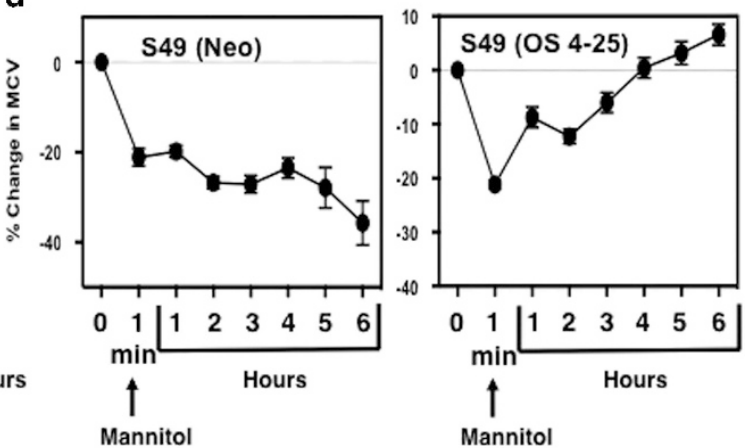

f

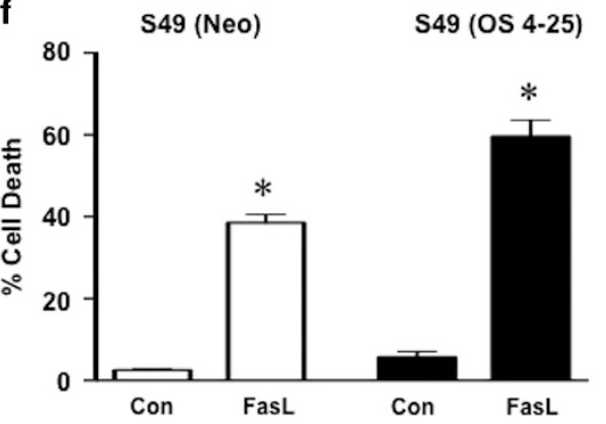

Figure 1 S49 (OS 4-25) cells are larger in size, acquired a RVI response, and are resistant to intrinsic apoptotic stimuli while remaining sensitive to extrinsic apoptotic stimuli. S49 Neo cells and S49 (OS 4-25) cells were examined for initial changes in cell size via light microscopy (a) and EV using a Cell Lab Quanta flow cytometer (b). After 25 generations of OS and recovery, the S49 (OS 4-25) cells are over twice the size as the parental S49 (Neo) cells. Data represent the mean ( \pm S.E.M.) of 7-8 independent experiments (c). S49 (Neo) and S49 (OS 4-25) cells treated with $250 \mathrm{mOsm}$ mannitol for various times and examined for loss of membrane integrity using propidium iodide (PI) and flow cytometry. Only the S49 (Neo) cells underwent apoptosis, whereas the S49 (OS 4-25) cells were resistant to this apoptotic stimulus (d). S49 (OS 4-25) cells treated with 250 mOsm mannitol showed a robust inherent RVI (right) that was absent in the S49 (Neo) cells (left; e). S49 (Neo) and S49 (OS 4-25) cells treated with $2.5 \mu$ m dexamethasone $(48 \mathrm{~h})$ were examined for cell viability. Only the $S 49$ (Neo) cells underwent apoptosis, whereas the S49 (OS 4-25) cells were resistant to this intrinsic apoptotic stimulus (f). In contrast, S49 (Neo) and S49 (OS 4-25) cells treated with $100 \mathrm{ng} / \mathrm{ml} \mathrm{Fas} \mathrm{Ligand} \mathrm{(24} \mathrm{h)} \mathrm{showed} \mathrm{sensitivity} \mathrm{to} \mathrm{receptor-mediated} \mathrm{cell} \mathrm{death.} \mathrm{Data} \mathrm{represent} \mathrm{the} \mathrm{mean} \mathrm{(} \pm$ S.E.M.) of $3-5$ independent experiments, ${ }^{*} P<0.001$ versus control

significant decrease in the extent of cell death was observed in the osmotically stressed S49 (Neo) cells in the presence of increasing concentrations of NAC, although the highest NAC concentration failed to fully protect these cells from death (Supplementary Figure 3). In contrast, caspase inhibition resulted in a clear concentration-dependent protection from cell death (Supplementary Figure 3), suggesting that ROS production has a substantial role in the cell death process; however, caspases has a critical role in inducing apoptosis in these cells. We examined the S49 (OS 4-25) cells for their response to the $\mathrm{BH} 3$ mimetic $\mathrm{ABT737}$, known to activate the intrinsic apoptotic pathway. The addition of ABT737 resulted in sensitizing the $S 49$ (OS 4-25) cells to undergo cell death, resulting in the release of cytochrome $c$ (Figure $4 \mathrm{f}$ ), indicating that the intrinsic cell death pathway remains intact. These data suggest a defect in signaling of the cell death program as a major cause of the selective apoptotic resistance in S49 (OS 4-25) cells.

S49 (OS 4-25) T cells show characteristics of the Warburg effect. An interesting phenotypic alteration was observed in the S49 (OS 4-25) cells, as after $48 \mathrm{~h}$ of culturing S49 (Neo) and S49 (OS 4-25) cells from an initial density of $1 \times 10^{5} \mathrm{cells} / \mathrm{ml}$ the culture media for the S49 (OS 4-25) cells appeared disproportionately acidic (Figure $5 \mathrm{a}$ ). This phenomenon can occur after excess growth; however, the S49 (OS 4-25) cells had significantly less number of cells when compared with the S49 (Neo) cells (Figure $5 \mathrm{~b}$ ). This acidic 


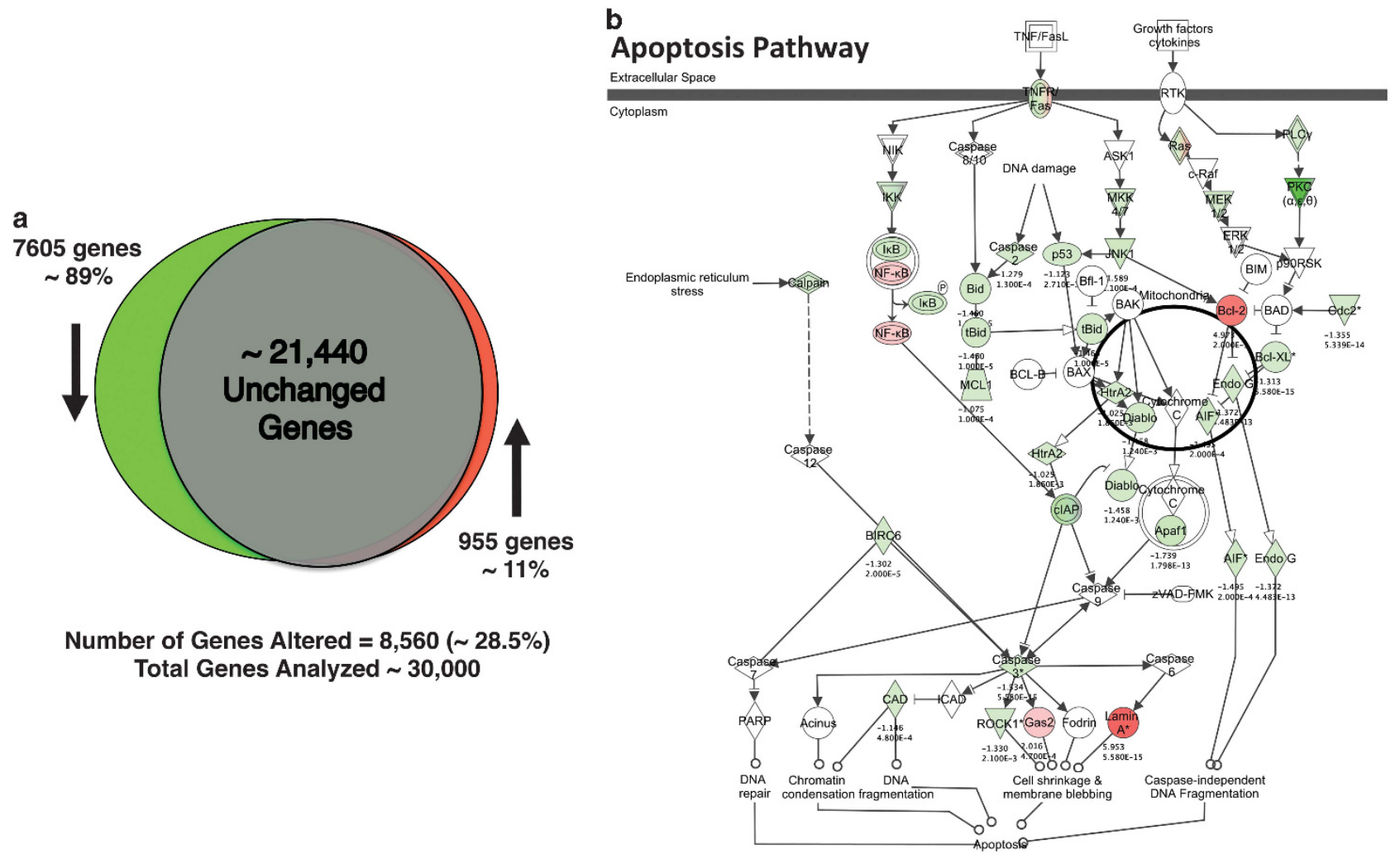

Figure 2 Genome-wide gene expression analysis for S49 (Neo) and S49 (OS 4-25) cells. (a) Venn diagram showing the total number and percent of altered probes, and probes with increased, decreased, and unchanged expression comparing the S49 (OS 4-25) cells with the S49 (Neo) cells. (b) Altered S49 (OS 4-25) genes involved in the apoptosis pathway

Table 1 Top 10 molecular and cellular functions in the S49 (OS 4-25) cells

\begin{tabular}{lc}
\hline Top molecular and cellular functions & No. of genes \\
\hline RNA posttranscriptional modification & 197 \\
Gene expression & 1007 \\
Cellular growth and proliferation & 1445 \\
Cell death and survival & 1487 \\
Posttranslational modification & 481 \\
DNA replication, recombination, and repair & 505 \\
Infectious disease & 730 \\
Organismal survival & 995 \\
Cell cycle & 741 \\
Embryonic development & 552 \\
\hline
\end{tabular}

environment observed for the S49 (OS 4-25) cells is characteristic of the Warburg effect, a high rate of glycolysis in the presence of oxygen that results in lactic acid fermentation. Our analysis showed a fivefold increase in intracellular lactate in the S49 (OS 4-25) cells compared with the S49 (Neo) cells (Figure 5c), suggesting metabolic reprogramming in the S49 (OS 4-25).

Lymphoid cells in general use glucose and glutamine as primary substrates to generate cellular energy. We examined the S49 (Neo) and S49 (OS 4-25) cells for their utilization of these cellular energy sources by culturing the cells in the absence of extracellular glucose or glutamine for $48 \mathrm{~h}$. Our data showed a $30-40 \%$ increase in dead cells for the S49
(Neo) cells under both conditions, whereas the S49 (OS 4-25) cells survived in the absence of glutamine, but had greater than $80 \%$ cell death in the absence of glucose (Figure $5 \mathrm{~d}$ ). These data indicate that the S49 (OS 4-25) cells have developed a unique and absolute requirement for glucose for survival, whereas the parental S49 (Neo) cells required both glucose and glutamine to maintain cell viability.

Altered AKT-mTOR signaling in the S49 (OS 4-25) cells results in apoptotic resistance. The shift in the S49 (OS 425) cells to glycolytic energy dependence suggests a change in the signaling mechanism(s) controlling the metabolism in these cells. Our analysis of various metabolic genes showed no significant change in gene expression in the S49 (OS 4-25) cells compared with the S49 (Neo) cells (Supplementary Figure 4). As AKT has been suggested to be an important driver of the glycolytic phenotype and is linked to many cellular processes including apoptosis and cell growth, we examined the $\mathrm{S} 49$ ( $\mathrm{Neo}$ ) and S49 (OS 4-25) cells for acute changes in the phosphorylation of AKT. Upon OS, an initial high level of activated phospho-AKT was lost in the S49 (Neo) cells, but sustained in the S49 (OS 4-25) cells (Figure 6a). As AKT is known to signal through mTOR, we examined the S49 (OS 4-25) cells for their response to inhibition of this kinase. Treatment of S49 (OS 4-25) cells with the mTOR inhibitor rapamycin resulted in the sensitization of these cells to apoptotic stimuli (Figure 6b), suggesting 
Table 2 Apoptotic genes with their change in gene expression in the S49 (OS 4-25) cells

\begin{tabular}{|c|c|c|c|}
\hline Symbol & Entrez gene name & Fold change & $P$-value \\
\hline LMNA & Lamin A/C & 5.953 & $5.58 \mathrm{E}-15$ \\
\hline BCL2 & B-cell CLL/lymphoma 2 & 4.973 & $2.00 E-05$ \\
\hline MRAS & Muscle RAS oncogene homolog & 3.572 & $1.40 \mathrm{E}-03$ \\
\hline FAS & Fas cell surface death receptor & 2.291 & $6.77 E-03$ \\
\hline GAS2 & Growth arrest-specific 2 & 2.016 & $4.70 E-04$ \\
\hline NFKB2 & Nuclear factor of kappa light polypeptide gene enhancer in B-cells 2 (p49/p100) & 1.959 & $6.00 E-05$ \\
\hline KRAS & Kirsten rat sarcoma viral oncogene homolog & 1.903 & $9.00 \mathrm{E}-05$ \\
\hline HTRA2 & HtrA serine peptidase 2 & -1.025 & $1.86 \mathrm{E}-03$ \\
\hline MAP2K4 & Mitogen-activated protein kinase kinase 4 & -1.034 & $1.82 \mathrm{E}-03$ \\
\hline MCL1 & Myeloid cell leukemia sequence 1 (BCL2-related) & -1.075 & 1.00E - 04 \\
\hline TP53 & Tumor protein p53 & -1.123 & $2.71 \mathrm{E}-03$ \\
\hline DFFB & DNA fragmentation factor, $40 \mathrm{kDa}$, beta polypeptide (caspase-activated DNase) & -1.146 & $4.80 \mathrm{E}-04$ \\
\hline RRAS2 & Related RAS viral ( $r$-ras) oncogene homolog 2 & -1.179 & $4.69 \mathrm{E}-07$ \\
\hline CAPN7 & Calpain 7 & -1.254 & $2.00 E-05$ \\
\hline IKBKG & Inhibitor of kappa light polypeptide gene enhancer in B-cells, kinase gamma & -1.264 & $8.00 E-05$ \\
\hline CASP2 & Caspase 2, apoptosis-related cysteine peptidase & -1.279 & $1.30 \mathrm{E}-04$ \\
\hline BIRC6 & Baculoviral IAP repeat containing 6 & -1.302 & $2.00 E-05$ \\
\hline MAP2K2 & Mitogen-activated protein kinase kinase 2 & -1.307 & $6.00 E-05$ \\
\hline BCL2L1 & BCL2-like 1 & -1.313 & $5.58 \mathrm{E}-15$ \\
\hline PLCG2 & Phospholipase C, gamma 2 (phosphatidylinositol-specific) & -1.319 & $5.58 E-15$ \\
\hline ROCK1 & Rho-associated, coiled-coil containing protein kinase 1 & -1.33 & $2.10 E-03$ \\
\hline CDK1 & Cyclin-dependent kinase 1 & -1.355 & $5.34 \mathrm{E}-14$ \\
\hline CHUK & Conserved helix-loop-helix ubiquitous kinase & -1.368 & $2.70 E-03$ \\
\hline ENDOG & Endonuclease G & -1.372 & $4.48 E-13$ \\
\hline XIAP & X-linked inhibitor of apoptosis & -1.419 & $2.00 E-05$ \\
\hline DIABLO & Diablo, IAP-binding mitochondrial protein & -1.458 & $1.24 \mathrm{E}-03$ \\
\hline BID & $\mathrm{BH} 3$ interacting domain death agonist & -1.46 & $1.00 E-05$ \\
\hline AIFM1 & Apoptosis-inducing factor, mitochondrion-associated 1 & -1.495 & $2.00 E-04$ \\
\hline CASP3 & Caspase 3 , apoptosis-related cysteine peptidase & -1.534 & $5.58 E-15$ \\
\hline NFKBIE & Nuclear factor of kappa light polypeptide gene enhancer in B-cell inhibitor, epsilon & -1.548 & $9.86 \mathrm{E}-10$ \\
\hline MAPK8 & Mitogen-activated protein kinase 8 & -1.589 & $1.10 E-04$ \\
\hline TNFRSF1B & Tumor necrosis factor receptor superfamily, member 1B & -1.701 & $1.09 E-14$ \\
\hline APAF1 & Apoptotic peptidase activating factor 1 & -1.739 & $1.80 \mathrm{E}-13$ \\
\hline NAIP & NLR family, apoptosis inhibitory protein & -2.397 & 4.17E-03 \\
\hline PRKCQ & Protein kinase C, theta & -5.74 & $1.08 E-11$ \\
\hline PRKCA & Protein kinase $\mathrm{C}$, alpha & -12.16 & $5.58 E-15$ \\
\hline
\end{tabular}

an alteration in the AKT-mTOR signaling pathway has a role in the observed apoptotic resistance.

Carbon source utilization and the Warburg effect alter the sensitivity of cells to undergo apoptosis. The findings of a complete dependence on glucose for S49 (OS 4-25) cell survival led us to examine the function of the mitochondria in these cells. Glycolytic metabolism of galactose yields no net ATP, forcing the cells to rely solely on oxidative phosphorylation for energy; ${ }^{38}$ thus, cells with dysfunctional mitochondria would die. Substitution of galactose for glucose resulted in cell survival and high viability of the S49 (OS 4-25) cells (Figure 7a), suggesting functional mitochondria. Methyl pyruvate as a surrogate for glucose also resulted in cell survival in the S49 (OS 4-25) cells (Figure 7a). Examination of both the S49 (Neo) and S49 (OS 4-25) cells for mitochondrial function using a Seahorse mitochondrial stress analysis (Figure 7b) showed similar oxygen consumption rate (OCR; left) and extracellular acidification rate (ECAR; right) profiles. The overall increase in ECAR in the S49 (OS 4-25) cells reflects the increased level of lactic acid in these cells (Figure $5 \mathrm{c}$ ); however, the addition of various mitochondrial stress reagents showed no difference in mitochondrial function between the two cell lines. As the S49 (OS 4-25) cells were viable in galactose and showed no mitochondrial dysfunction, we determined if galactose could sensitize these cells to undergo apoptosis. When S49 (OS 4-25) cells were cultured in galactose for $48 \mathrm{~h}$ before exposure to OS, $\sim 40 \%$ of the cells died within $6 \mathrm{~h}$, compared with cells cultured in glucose (Figure 7c). These data suggest that a change in carbon source (galactose) that permits predominantly oxidative phosphorylation as the primary mechanism for energy production can sensitize cells to undergo cell death.

We tested the hypothesis that heightened glycolysis can result in apoptotic resistance by using primary $T$ cells isolated from the mouse spleen as a model system. Naïve $T$ cells generate ATP via oxidative phosphorylation, whereas activated $T$ cells predominately rely on glycolysis as the major mode of energy generation even in the presence of sufficient oxygen (Warburg effect). The naïve T cells were significantly more sensitive to apoptotic stimulation than the anti-CD3/ CD28-activated T cells (Figure 7d), suggesting that activated T cells, similar to our S49 (OS 4-25) cells that predominately use glycolysis as a source of energy, have increased resistance to cell death.

Glucose withdrawal reverses the resistance to cell death. We analyzed the mode of cell death in the S49 (OS 4-25) cells after 30-36 h of glucose withdrawal for changes in various core characteristics associated with apoptosis. As 
shown in Figure 8a, glucose withdrawal from the S49 (OS 4-25) cells resulted in propidium iodide-positive $\left(\mathrm{PI}^{+}\right)$cells with a slight decrease in forward-angle light scatter indicative of a reduced cell size. The loss of cell volume in the S49
(OS 4-25) is most likely opposed by the gain of a RVI response in these cells (Figure 1d), restricting the extent of this parameter. To directly address this issue of cell volume changes, we measured the mean cell volume (MCV) via
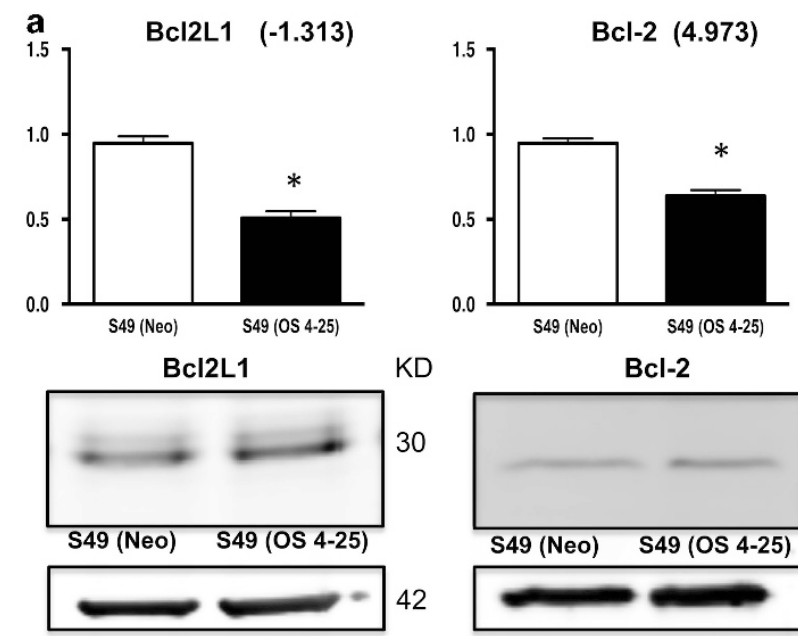

KD
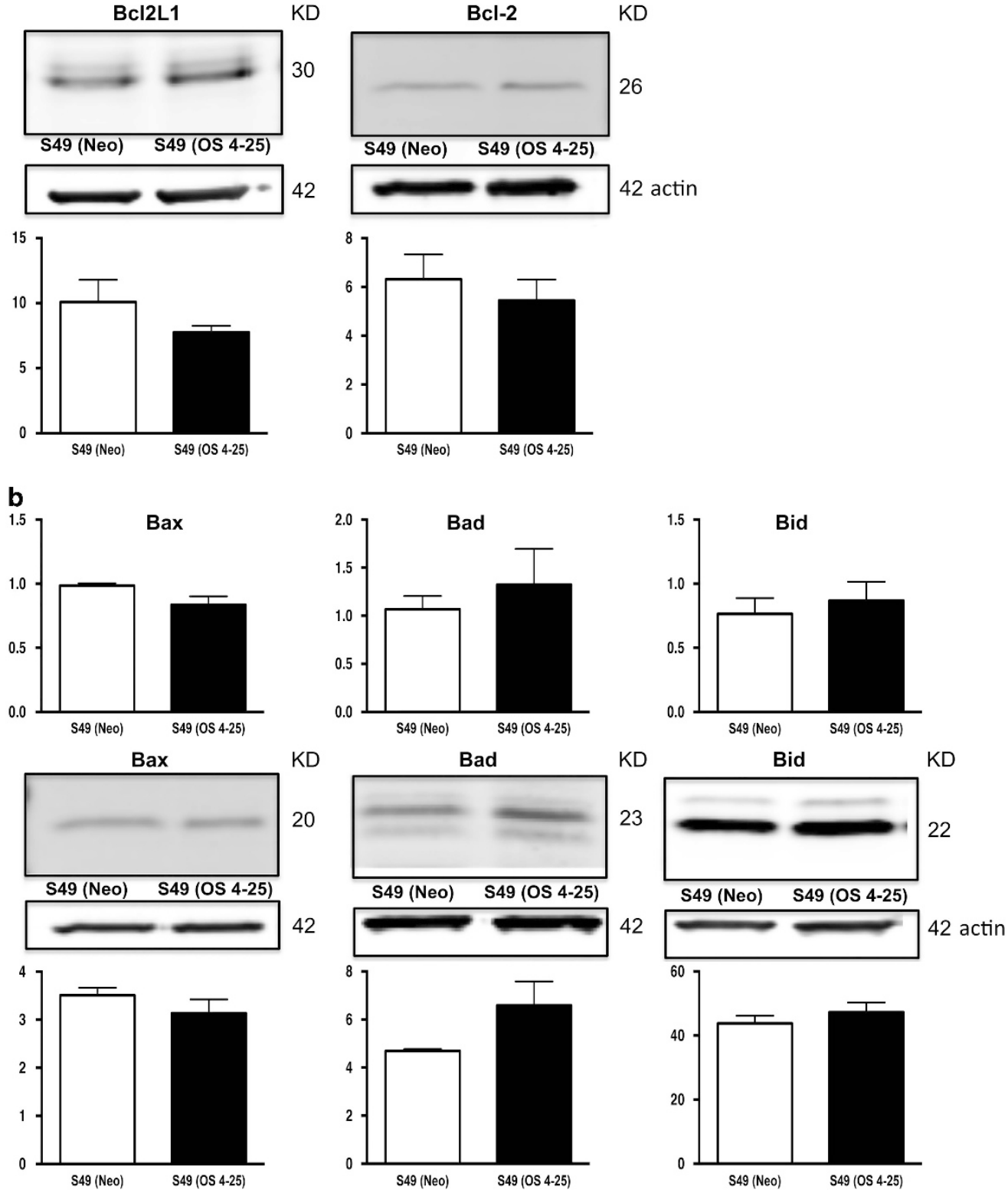

Figure 3 mRNA and protein expression levels of various Bcl-2 family members in S49 (Neo) and S49 (OS 4-25) cells. (a) Antiapoptotic Bcl-2 family members Bcl2L1 (Bcl-xL) and Bcl-2 were examined for changes at both the mRNA and protein levels, each showing a significant decrease in mRNA levels in the S49 (OS 4-25) cells; however, there was no significant change at the protein level. (b) Proapoptotic Bcl-2 family members Bax, Bad, and Bid were also examined for changes at both the mRNA and protein level. No significant change in either mRNA or protein levels was observed. (c) Additional Bcl-2 family members Bim, PUMA, Mcl-1, and NOXA were examined for changes in mRNA. No significant change was observed in any of the Bcl-2 family members. Data represent mean ( \pm S.E.M.) of three independent experiments, ${ }^{*} P<0.05$ versus control 

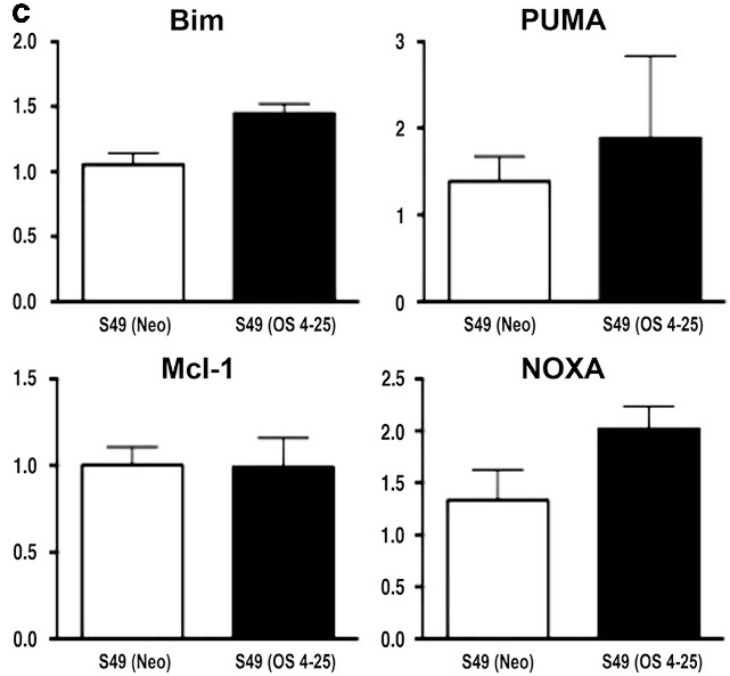

Figure 3 Continued

electronic sizing in the viable population of cells in the presence and absence of glucose, observing a $13.3 \pm 3.9 \%$ decrease in MCV in the S49 (OS 4-25) cells grown without glucose. These glucose-starved cells also show an increase in caspase-3/7 activity, ROS production, and intracellular calcium, coupled with a loss of glutathione and a well-defined internucleosomal DNA cleavage pattern (Figure 8b and f), all characteristic of cells undergoing apoptosis. Both examination of these cells for changes in their membrane lipid symmetry (externalization of phosphatidylserine) and release of cytochrome $c$, showed a significant increase in the $\mathbf{S 4 9}$ (OS 4-25) cells in the absence of glucose (Figure $8 \mathrm{~g}$ and $\mathrm{h}$, respectively). Thus, the absence of glucose from the S49 (OS 4-25) cells results in the occurrence of several fundamental cell death characteristics reflective of essential apoptosis.

\section{Discussion}

This study shows that repetitive OS and recovery of lymphoid cells results in permanent global changes at both the genetic and metabolic levels, which has consequences leading to aberrant cell signaling and activation of intrinsic apoptosis. These cellular transformations involved a change in cell size, a loss of essential characteristics associated with intrinsic apoptosis, and a complete dependence on glucose as an energy source, while maintaining sensitivity to extrinsic stimuli. Interestingly, glucose withdrawal from the S49 (OS 4-25) cells resulted in cell death with many classical characteristic of apoptosis, including cell shrinkage, increased intracellular calcium, increased caspase activity, loss of cytochrome $c$, externalization of phosphatidylserine, and internucleosomal DNA cleavage. Galactose as an alternative carbon source for glucose resulted in sensitizing these cells to apoptosis. These data suggest that the global cell death machinery remains intact in the S49 (OS 4-25) cells, and the resistance to apoptosis is associated with alterations in signal transduction pathways that activate the apoptotic program.
We previously showed that S49 (Neo) cells are devoid of a $\mathrm{RVI}$ response and undergo a very rapid and synchronous apoptosis. ${ }^{39}$ In an earlier generation of stressed and recovered cells, we demonstrated that OS resistance imparts acquired antiapoptotic mechanisms through an acquired RVI response and AKT signaling that combats the ionic changes associated with cell shrinkage. ${ }^{28}$ Our current study uses cells that were carried through an additional 10 generations of OS and recovery, resulting in a more stable population of cells. We show here that the activation of the AKT signaling is retained in the S49 (OS 4-25) cells and extended this finding, showing that mTOR also has a critical role in the intrinsic apoptotic resistance. In addition, the discord between the intrinsic apoptotic resistance of S49 (OS 4-25) cells and their ability to die upon glucose deprivation or their sensitization to die in the presence of galactose suggests that an appropriate carbon source for energy is a critical requirement to initiate the cell death program. Therefore, the signaling or activation of the S49 (OS 4-25) cells to apoptosis is compromised in both a stimulus- and/or metabolic-specific manner.

Analysis of genome-wide changes in gene expression showed $28.5 \%$ of all genes in the S49 (OS 4-25) cells were significantly altered with $89 \%$ of these genes having reduced gene expression, suggesting an overall suppression of the transcriptional activity or increased RNA turnover in the $\$ 49$ (OS 4-25) cells. Pathway analysis of the S49 (OS 4-25) cells affected several important molecular and cellular functions. The reduced expression of genes is particularly evident in the apoptosis pathway, where 29 of 36 S49 (OS 4-25) genes (81\%; Table 2) had diminished expression. Of note, the Fas cell surface death receptor showed increased gene expression in the S49 (OS 4-25) cells, supporting our finding that these cells remain sensitive to extrinsic apoptotic stimuli and the core cell death machinery remains intact. In-depth analysis of both pro- and antiapoptotic Bcl-2 family members showed no marked changes in either mRNA or protein that could account for the selective cell death resistance in the S49 (OS 4-25) cells. Overall, the genetic adaptations observed in the S49 (OS 4-25) cells indicate a tendency to promote cell survival under adverse conditions and resistance to apoptosis in this paradigm likely reflects numerous changes in cellular gene expression.

T cells meet their basal energy demands by utilizing an aerobic process to metabolize glucose to pyruvate, which in turn enters the mitochondria to generate ATP via the tricarboxylic acid cycle and oxidative phosphorylation. ${ }^{40}$ Activated $\mathrm{T}$ cells change their metabolic state by utilizing aerobic glycolysis. ${ }^{41-43}$ The high rate of glycolysis in activated $T$ cells bypasses the normal oxidation of pyruvate in the mitochondria, resulting in lactic acid fermentation, whereas minimal lactic acid production occurs in resting cells. ${ }^{44}$ In our study, we show that CD3/CD28-activated T cells from mouse spleen exhibited significant resistance to apoptosis compared with their naïve/resting counterparts, suggesting that heightened glycolysis as reported in activated cells, and observed in the $\$ 49$ (OS 4-25) cells, can have a key role in the cell death program.

A key finding in our study was the absolute requirement for glucose as an energy source in the S49 (OS 4-25) cells. Even though energy depletion has been classically associated with 

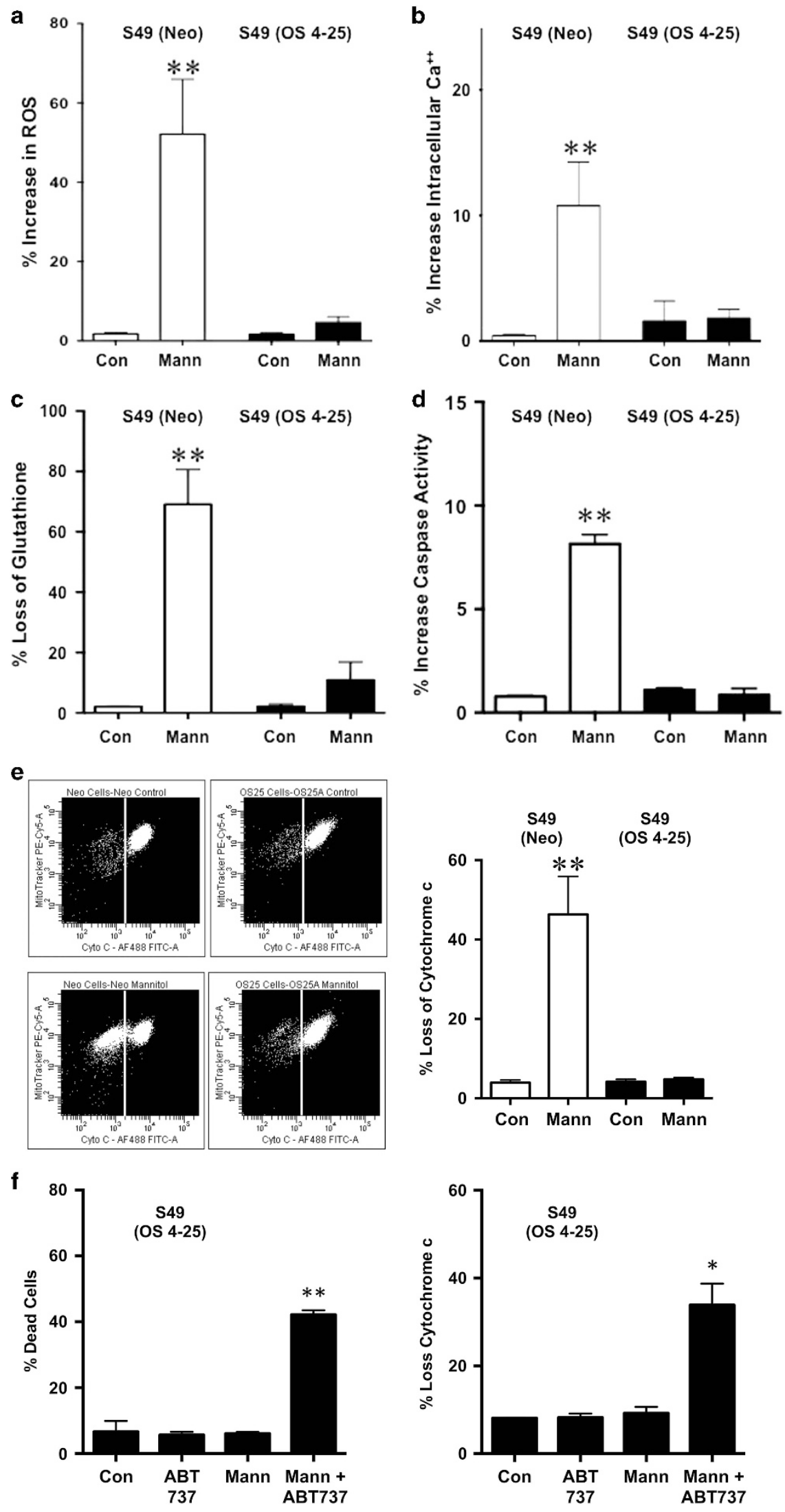
necrosis, the S49 (OS 4-25) cells in the absence of glucose display many characteristics of apoptosis. Recently, cross talk between cell death and the ability of cells to utilize a variety of carbon substrates has begun to be established, ${ }^{27}$ and the switch from one substrate to another can have protective effects on a cell fate. ${ }^{45,46}$ The generation of S49 (OS 4-25) cells has resulted in a carbon substrate reprogramming characteristic of the Warburg effect, which we show offers a selective survival advantage to these cells and has a critical role in whether a cell lives or dies. Collectively, our data suggest that repetitive stress and recovery results in genetic changes that are not restricted to commonly studied pro- or antiapoptotic genes, and these genetic changes result in a modification of carbon substrate utilization for energy production that impinges on the cell's ability to activate or signal apoptosis.

\section{Materials and methods}

Cell culture and chemicals. S49 Neo cells are S49.1 mouse lymphoma cells stably infected with a recombinant amphotropic retrovirus carrying a G418 antibiotic resistance gene. ${ }^{20}$ Cells were maintained in RPMI- 1640 supplemented with $10 \%$ heat-inactivated fetal calf serum, $4.8 \mathrm{mM}$ glutamine, $100 \mu \mathrm{g} / \mathrm{ml}$ streptomycin, and $100 \mathrm{U} / \mathrm{ml}$ penicillin at $37^{\circ} \mathrm{C}$, in $7 \% \mathrm{CO}_{2}$ atmosphere. Standard
RPMI-1640 was made hyperosmotic by the addition of solid mannitol before the addition of the supplemental components. RPMI-1640 media without glucose or glutamine was purchased through Life Technologies (Grand Island, NY, USA). Dexamethasone was purchased through Steraloids (Witton, NH, USA), and Fas ligand was purchased through Kamiya Biomedical (Seattle, WA, USA).

Generation of OS cells. S49 Neo cells were exposed to RPMI-1640 media containing $500 \mathrm{mM}$ mannitol for $4 \mathrm{~h}$ at $37^{\circ} \mathrm{C}$, in $7 \% \mathrm{CO}_{2}$ atmosphere. After this time, the cells were centrifuged at 3000 r.p.m., then returned to normal RPMI- 1640 media, and incubated at $37^{\circ} \mathrm{C}$, in $7 \% \mathrm{CO}_{2}$ atmosphere. Over a period of $7-10$ days of culture, the surviving cells regenerated to a viable population of cells in the presence of normal RPMI- 1640 media. This protocol was repeated to generate cells that were repetitively exposed to $500 \mathrm{mM}$ mannitol for $4 \mathrm{~h}$, then recovered for 25 generations.

Cell volume analysis. Cell volume was determined via electronic sizing using a Cell Lab Quanta flow cytometer (Beckman Coulter, Indianapolis, IN, USA) equipped with a 488-nm laser. The electronic volume (EV) channel was calibrated using Flow-Check Fluorospheres (10.4 $\mu \mathrm{m}$; Beckman Coulter). Cells at a density of $1 \times 10^{6} \mathrm{cells} / \mathrm{ml}$ were centrifuged and resuspended in normal or hypertonic RPMI-1640 media and examined as described in the results. An EV gate was used to eliminate cell debris and to exclude portions of cells (apoptotic bodies) that may be formed and released during apoptosis. The percent change in MCV was determined by subtracting the hypertonic MCV value from the normal control MCV value (x100) for each individual time point. a

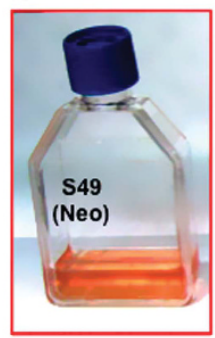

b

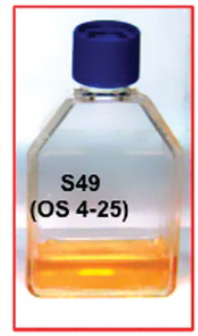

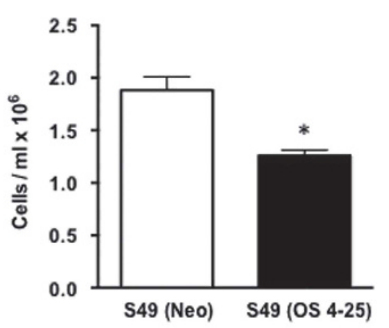

c

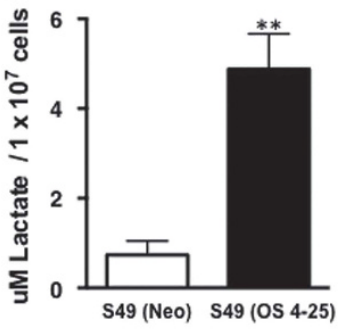

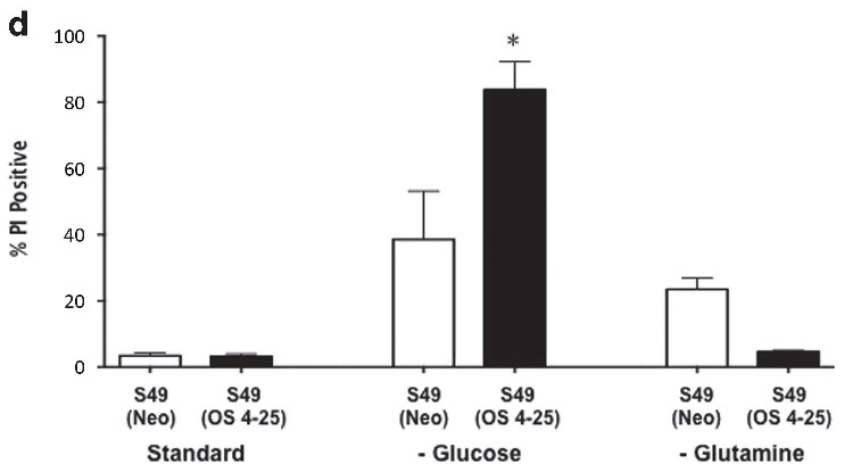

Figure 5 S49 (OS 4-25) cells have classic characteristics of the Warburg effect and require glucose for cell survival. S49 (Neo) and S49 (OS 4-25) cells from a starting concentration of $1 \times 10^{5} \mathrm{cells} / \mathrm{ml}$ in standard RPMI-1640 media were cultured for $48 \mathrm{~h}$. (a) The S49 (OS 4-25) cells have an increase in acidity, as reflected in the yellowing of the media compared with the $\mathrm{S} 49(\mathrm{Neo})$ cells. However, (b) there was a decreased number of cells per ml after $48 \mathrm{~h}$ culture in standard RPMl-1640 media. (c) Analysis of the intracellular lactate concentration shows a fivefold increase in the S49 (OS 4-25) cells compared with the S49 (Neo) cells. (d) S49 (Neo) and S49 (OS 4-25) cells were cultured in standard RMPI-1640 media, RPMI-1640 media without glucose, or RPMI-1640 media without glutamine for $48 \mathrm{~h}$. The S49 (OS 4-25) cells showed a complete dependence on glucose as an energy source, whereas the $S 49$ (Neo) cells were only mildly sensitive to either glucose or glutamine withdrawal. Data represent the mean ( \pm S.E.M.) of 3-6 independent experiments, ${ }^{\star} P<0.05,{ }^{*} P<0.01$ versus control

Figure 4 S49 (OS 4-25) cells lack signaling characteristic of apoptosis. S49 (Neo) and S49 (OS 4-25) cells were treated with 250 mOsm mannitol for 4-6 h, then examined for (a) an increase in mitochondrial-derived ROS using MitoSox, (b) an increase in intracellular calcium using Fluor-4, (c) the loss of glutathione using mBCl, and (d) the presence of caspase activity by flow cytometry. Only the $S 49$ (Neo) cells undergoing apoptosis showed changes characteristic of apoptosis (e). In addition, the release of cytochrome $c$ was also only observed in the S49 (Neo) cells (f). S49 (OS 4-25) cells treated with or without $1 \mu \mathrm{m} \mathrm{ABT373} \mathrm{and} 250 \mathrm{mOsm}$ mannitol (6 h) results in cell death along with the loss of cytochrome $c$. Data represent the mean ( \pm S.E.M.) of 3-5 independent experiments, ${ }^{*} P<0.05,{ }^{* \star} P<0.01$ versus control 

NEO
OS4-25

Con $15 \quad 30$

4560 Con

$15 \quad 30 \quad 45$

60

Min (250mOsm mannitol)
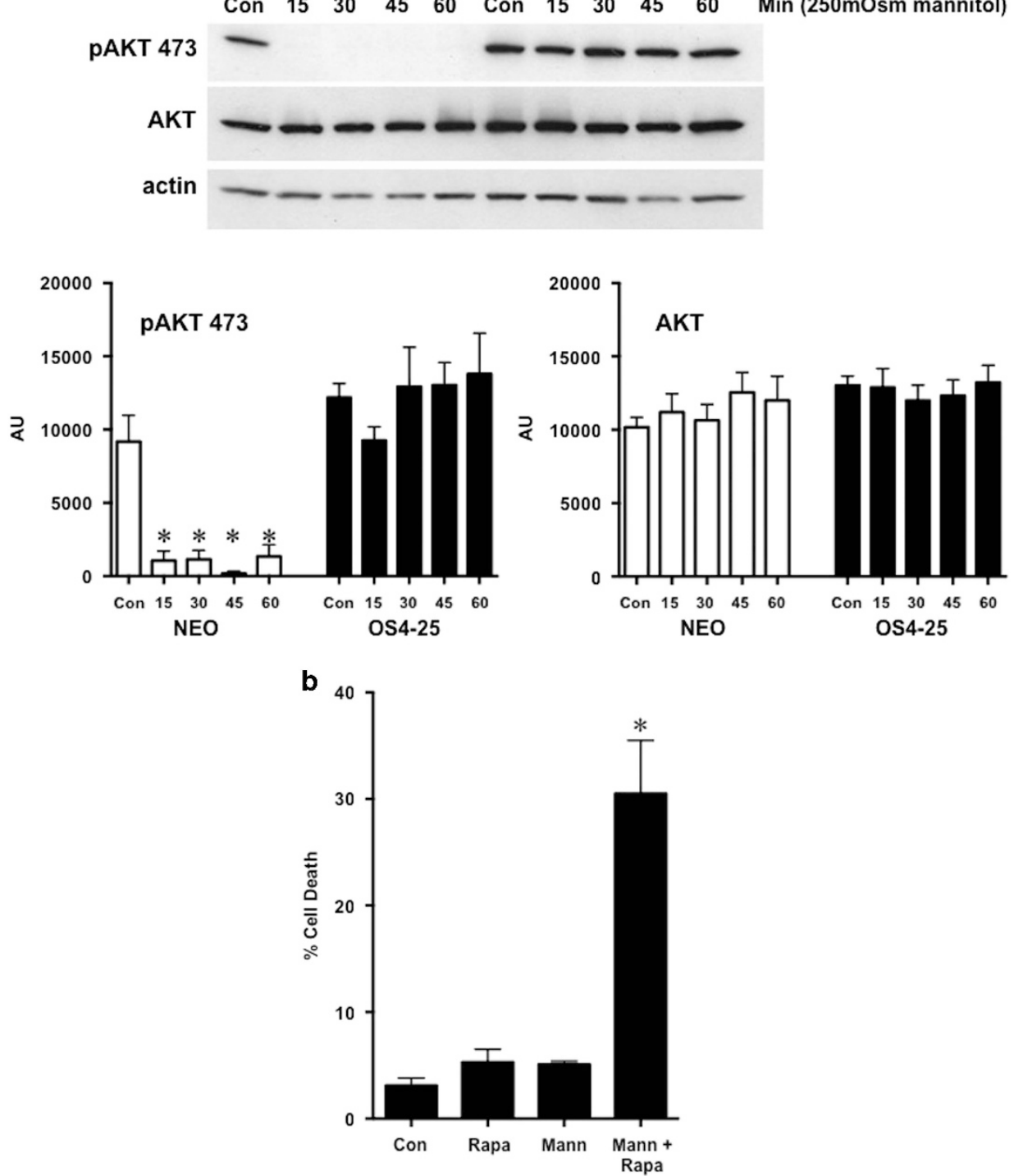

Figure 6 Altered AKT-mTOR signaling in the S49 (OS 4-25) cells. (a) S49 (Neo) and S49 (OS 4-25) cells were examined for changes in AKT and pAKT expression after treatment with $250 \mathrm{mOsm}$ mannitol for various times. The S49 (Neo) cells showed a striking decrease in activated pAKT expression compared with the S49 (OS 4-25) cells. (b) S49 (OS 4-25) cells treated with or without $15 \mu \mathrm{m}$ rapamycin and $250 \mathrm{mOsm}$ mannitol (6h) result in cell death. Data represent the mean ( \pm S.E.M.) of 3-5 independent experiments, ${ }^{\star} P<0.05$

Flow cytometric analysis of caspase activity, calcium, ROS, glutathione, and membrane lipid symmetry. Caspase activity for caspase-3/7-like enzymes was accomplished using a CaspaTag in situ assay kit (Chemicon, Temecula, CA, USA) according to the manufacturer's instructions. Briefly, $1 \mathrm{~h}$ before cytometric analysis, $300 \mu$ l of cells were added to $10 \mu \mathrm{l}$ of a $30 \mathrm{x}$ CaspaTag reagent working stock and incubation was continued. Immediately before cytometric analysis, the cells were washed in $2 \mathrm{ml}$ of CaspaTag wash buffer, resuspended in $500 \mu \mathrm{l}$ of $1 \mathrm{x}$ phosphate-buffered saline (PBS), and $2 \mu \mathrm{l}$ of PI (supplied in the kit) was added to each sample. Intracellular calcium was determined by adding Fluo-3 ( $1 \mu \mathrm{M}$ final; Life Technologies) to each sample for $30 \mathrm{~min}$ at $37^{\circ} \mathrm{C}, 7 \% \mathrm{CO}_{2}$ atmosphere before examination. Caspase inhibitor Q-VD-OPh was purchased from Sigma (St Louis, MO, USA). Analysis of mitochondrial ROS was done by adding MitoSox Red ( $5 \mu \mathrm{M}$ final; Life Technologies) to each sample for $30 \mathrm{~min}$ at $37^{\circ} \mathrm{C}$, in $7 \% \mathrm{CO}_{2}$ atmosphere before examination. Analysis of intracellular glutathione was done by adding monochlorobimane ( $\mathrm{mBCl} ; 10 \mu \mathrm{M}$ final; Life Technologies) to each sample for $10 \mathrm{~min}$ at $37^{\circ} \mathrm{C}$, in $7 \% \mathrm{CO}_{2}$ atmosphere before examination. $\mathrm{Pl}$ (10 $\mu \mathrm{g} / \mathrm{ml}$; Sigma) or Sytox Blue ( $5 \mu \mathrm{M}$; Life Technologies) was used as vital dye and was added immediately before flow cytometric examination. Phosphatidylserine symmetry was determined using Annexin- $V$ conjugated to fluorescein isothiocyanate (Trevigen, Gaithersburg, MD, USA) according to the manufacturer's instructions. All samples were analyzed using a Becton Dickinson LSRII (San Jose, CA, USA) equipped with FACSDiVa software for acquisition and analysis. For each sample, cells were excited with a 488-nm laser and detected at $530 \mathrm{~nm}$ (CaspaTag, Fluo-3, Annexin-V), a $561-\mathrm{nm}$ laser and detected at $585 \mathrm{~nm}$ (PI, MitoSox), and/or a 405-nm laser and detected at $440 \mathrm{~nm}(\mathrm{mBCl}$, Sytox Blue). Only cells that did not lose their membrane integrity (PI negative) were included in the analysis for caspase activity, calcium, ROS, and glutathione.

Flow cytometric analysis for cytochrome $c$ release. Cells were initially stained with MitoTracker Deep Red ( $200 \mathrm{nM}$ final; Life Technologies) for $30 \mathrm{~min}$ at $37^{\circ} \mathrm{C}$, in $7 \% \mathrm{CO}_{2}$ atmosphere before harvest. The cells were washed once in $1 x$ PBS, resuspended in 500 CytoFix (BD Biosciences, San Jose, CA, USA) while vortexing, and held at room temperature for $30 \mathrm{~min}$, after which $1 \mathrm{ml}$ of Perm Wash buffer (BD Biosciences) was added. The cells were centrifuged, resuspended in $100 \mu \mathrm{l}$ of Perm Wash buffer, and stored overnight at $4^{\circ} \mathrm{C}$. The next day, $2 \mu \mathrm{l}$ of a $1: 10$ dilution of an Alexa Fluor 488 anti-cytochrome $c$ antibody (BioLegend) and 
a
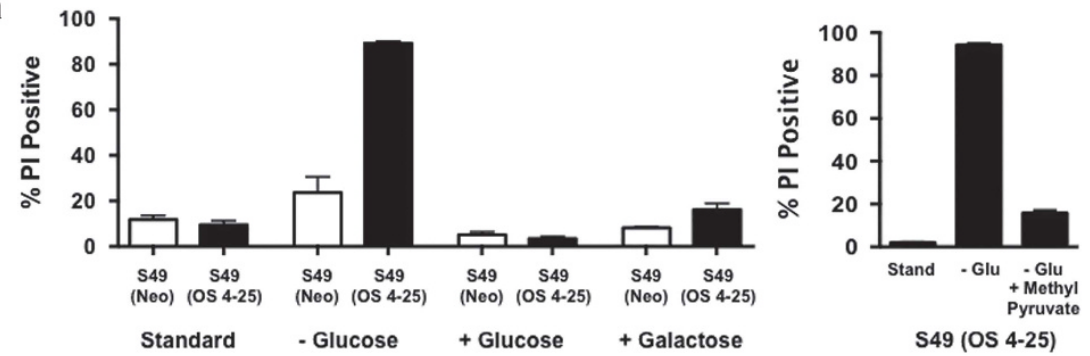

b
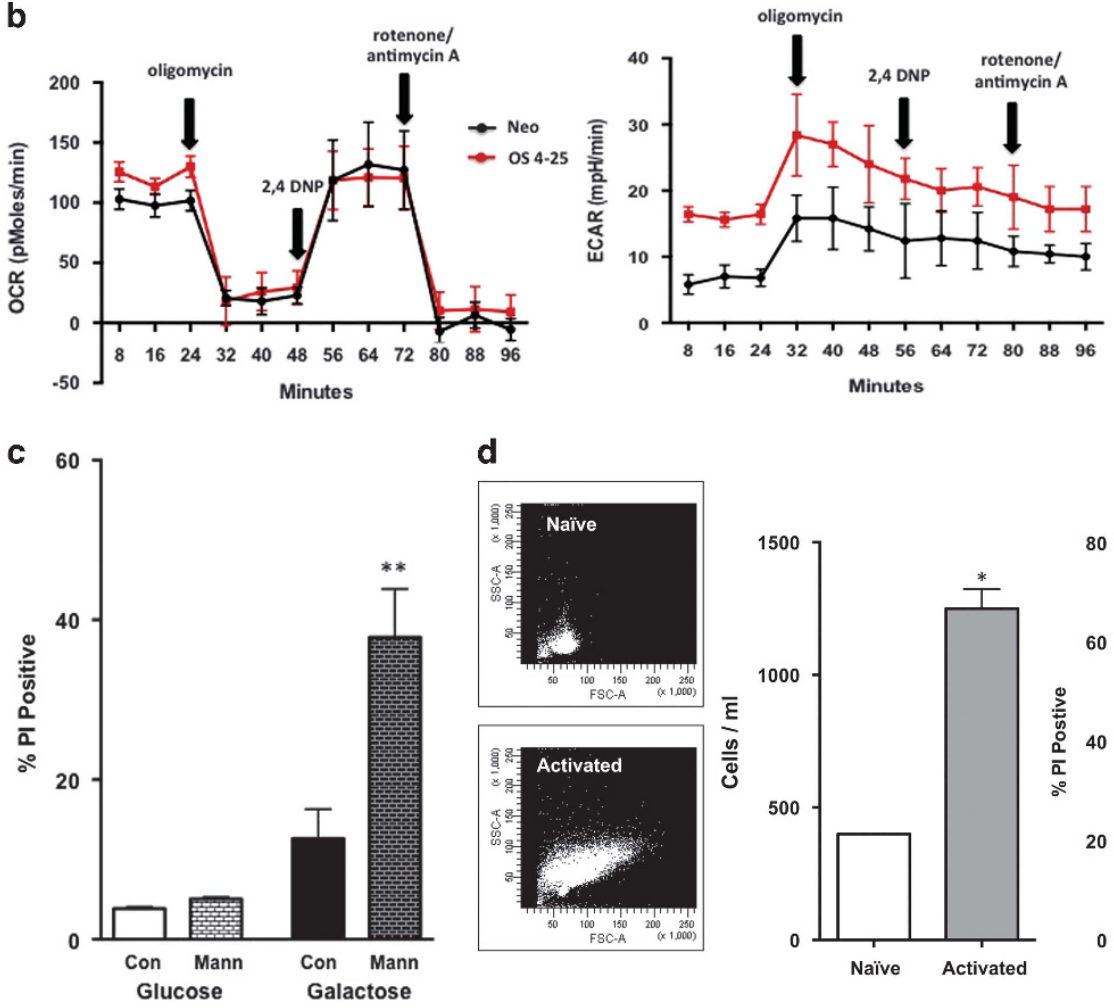

d

Figure 7 Carbon substrate substitution and heightened glycolysis impact the activation of apoptosis. (a) S49 (Neo) and S49 (OS 4-25) cells were cultured in standard RMPI-1640 media, RPMI-1640 media without glucose, or RPMl-1640 media with $111 \mathrm{mM}$ glucose or $11 \mathrm{mM}$ galactose for $48 \mathrm{~h}$. The addition of either glucose or galactose protected the cells from cell death. In addition, methyl pyruvate also protected the S49 (OS 4-25) cells from glucose deprivation after $48 \mathrm{~h}$. Data represent the mean ( \pm S.E.M.) of 3-6 independent experiments. (b) Cellular respiration of S49 (Neo) and S49 (OS 4-25) cells analyzed by the mitochondrial stress test. Both the OCR and ECAR showed no significant difference between the two cell lines in regard to the function of the mitochondria. The graph represents one of three similar experiments. (c) S49 (OS 4-25) cells cultured in galactose for $48 \mathrm{~h}$ before exposure to $250 \mathrm{mOsm}$ mannitol showed an increase in sensitivity to cell death that is absent in the presence of glucose. Data represent the mean ( \pm S.E.M.) of five independent experiments. ${ }^{* *} P<0.01$ versus control. (d) Naïve and activated $C D 4+T$ cells from mouse spleen were examined for sensitivity to undergo cell death. CD3/CD28 stimulated CD4+ T cells exhibited an increase in cell size (left panel) and cell number (middle panel), both characteristics of activated T cells. Treatment of the naïve T cells with $250 \mathrm{mOsm}$ mannitol for $8 \mathrm{~h}$ showed significantly more sensitivity in undergoing cell death than their activated counterparts. Data represent the mean ( \pm S.E.M.) of three independent experiments, ${ }^{*} P<0.05$

DAPI (50 ng/ml final) was added to each sample, incubated at room temperature for $60 \mathrm{~min}$, after which $500 \mu \mathrm{l}$ of Perm Wash buffer was added. The cells were centrifuged, resuspended in $200 \mu \mathrm{l}$ of Perm Wash buffer, and examined by flow cytometry using a Becton Dickinson LSRII equipped with FACSDiVa software for acquisition and analysis. For each sample, cells were excited with a 488-nm laser and detected at $530 \mathrm{~nm}$ (AF488-cytochrome c), a 56-nm laser and detected at $660 \mathrm{~nm}$ (MitoTracker Deep Red), and a 405-nm laser and detected at $440 \mathrm{~nm}$ (DAPI).

Mitochondrial stress analysis. A total of 120000 cells/well in DMEM XF assay media supplemented with $10 \mathrm{mM}$ glucose and $1 \mathrm{mM}$ sodium pyruvate were plated in a XF 24-well plate (Seahorse Bioscience, North Billerica, MA, USA), which was initially coated with $34 \mu \mathrm{g} / \mathrm{ml}$ Corning Cell Tak (Fisher Scientific, Houston, TX, USA) prepared using $0.1 \mathrm{M} \mathrm{NaHCO}_{3}$ ( $\mathrm{pH}$ 8.0). OCR were determined in situ using a
Seahorse Extracellular Flux Analyzer (Seahorse Bioscience). Baseline oxygen consumption was measured three times for 3 min following a 3-min mix and 2-min wait period. Following determination of the basal OCR, oligomycin ( $1 \mu \mathrm{M}$ final), 2,4, DNP $(150 \mu \mathrm{M}$ final), and rotenone/antimycin $\mathrm{A}(0.5 \mu \mathrm{M}$ final) were added consecutively using the same three cycle $-3 \mathrm{~min}-2 \mathrm{~min}-3 \mathrm{~min}$ mix, wait, and measure protocol.

Intracellular lactate assay. Intracellular lactate was determined using an L-lactate assay kit (Fluoro Lactate, Cell Technology Inc., Mountain View, CA, USA) according to the manufacturer's instructions. A lactate standard curve was generated according to the manufacturer's instructions. Samples were read using a POLARstar omega microplate reader (BMG Labtech, Cary, NC, USA) with an excitation/emission of $544 / 590 \mathrm{~nm}$, respectively. 

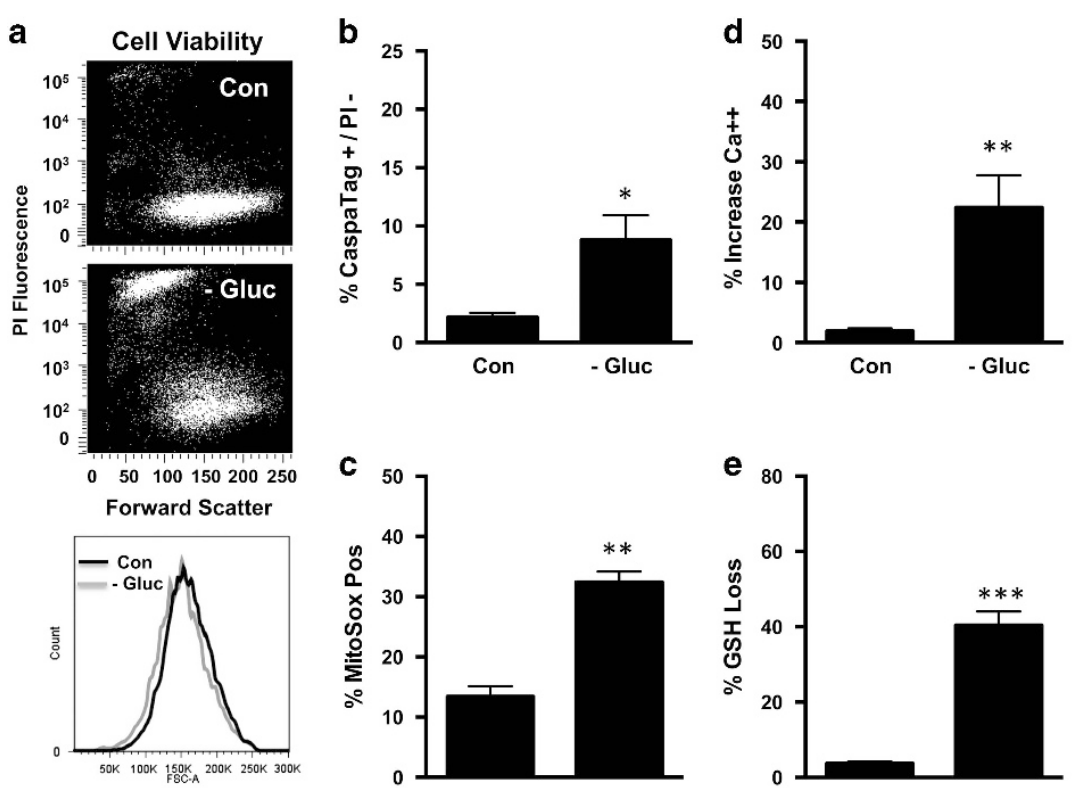

f DNA

Degradation
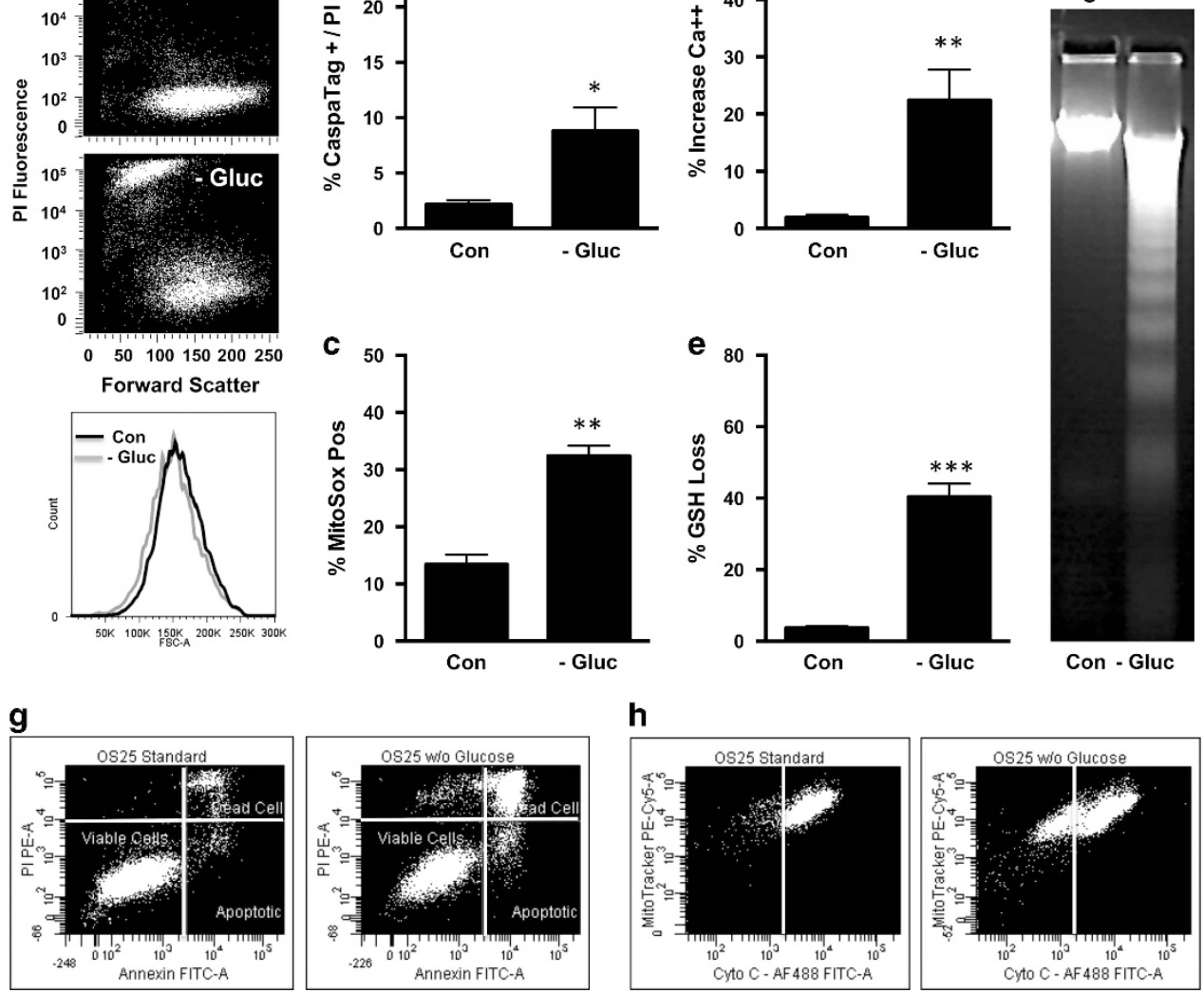

h
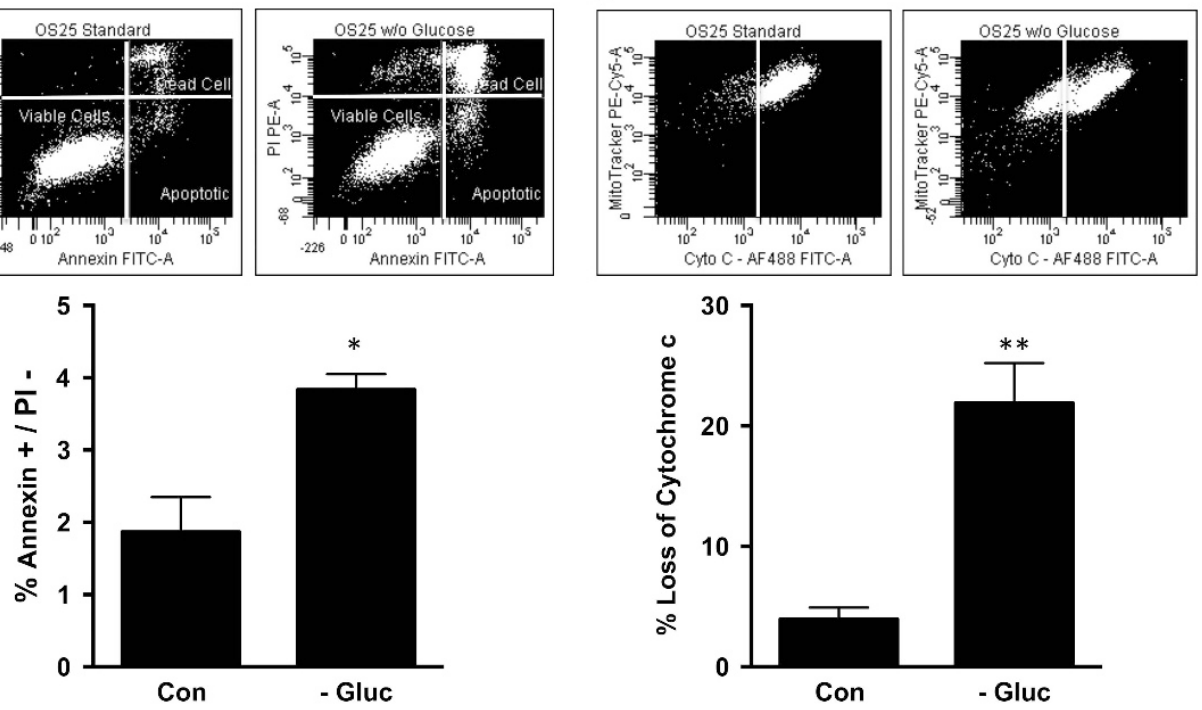

Figure 8 S49 (OS 4-25) cells undergo cell death resembling apoptosis in the absence of glucose. S49 (OS 4-25) cells cultured in the absence of glucose were examined for (a) changes in cell size in relation to the loss of plasma membrane integrity, (b) caspase activity, (c) ROS activity, (d) calcium, (e) glutathione, (f) DNA degradation, (g) changes in membrane lipid symmetry, and (h) cytochrome $c$. In the absence of glucose, S49 (OS 4-25) cells showed a loss of cell volume, an increase in caspase activity, mitochondrialderived ROS, intracellular calcium, and externalization of phosphatidylserine, along with a loss of intracellular glutathione and cytochrome $c$. Examination of the DNA integrity showed a 'ladder-like' pattern of DNA cleavage characteristic of apoptosis. Data represent the mean ( \pm S.E.M.) of $3-4$ independent experiments, ${ }^{\star} P<0.05$, ${ }^{\star} P<0.01$, ${ }^{* * \star} P<0.001$ versus control

DNA isolation. DNA from the S49 (Neo) and S49 (OS 4-25) cells was isolated using DNeasy Blood \& Tissue Kit (Qiagen, Germantown, MD, USA) according to the manufacturer's instructions. Samples were quantified using a spectrophotometer (Nanodrop-ND-1000; Thermo Scientific, Waltham, MA, USA), and purity was analyzed by the $260 / 280 \mathrm{~nm}$ absorbance ratios. Five micrograms of DNA was analyzed on a $1.8 \%$ agarose gel using $1 \times$ TAE (tris-acetate-EDTA) running buffer. Before casting the gel, GelRed Nucleic Acid Stain (Phenix Research Products, Candler, NC, USA) was added at a 1:10000 dilution.

RNA isolation. Total RNA from the S49 (Neo) and S49 (OS 4-25) cells was isolated using the QIAshredder and RNeasy mini-kit (Qiagen) according to the manufacturer's instructions. DNase treatment was performed on column using a ribonuclease-free DNase kit (Qiagen) according to the manufacturer's instructions. Samples were quantified using a spectrophotometer (NanodropND-1000; Thermo Scientific), and purity was analyzed by the $260 / 280 \mathrm{~nm}$ absorbance ratios.

Quantitative RT-PCR. Quantitative RT-PCR was performed with a 7900HT sequence detection system using predesigned primer-probe sets (Life Technologies) according to the manufacturer's instructions. RT-PCR assays were performed using the two-step method: cDNAs were generated from $4 \mu \mathrm{g}$ of total RNA using reverse transcriptase reagents (Life Technologies), then RT-PCR was performed using the universal master mix (Life Technologies). The signal obtained from each gene primer-probe set was normalized to the housekeeping gene peptidylprolyl isomerase $\mathrm{B}$. The delta-delta $\mathrm{Ct}$ method of analysis and $\mathrm{RQ}$ transformation were used to plot the data. 
Naïve CD4+ T-cell isolation and stimulation. C57BL/6 mice were used and were cared for according to the guidelines of the Animal Care and Use Committee of the National Institute of Environmental Health Sciences, National Institutes of Health. Mouse naïve CD4+ T cells were isolated from the spleen using the EasySep negative selection isolation kit from Stem Cell Technologies (Vancouver, BC, Canada) according to the manufacturer's instructions. Naiive CD4+ T cells were stimulated using Dynabeads Mouse T-Activator CD3/CD28 from Life Technologies at a 1:1 bead-to-cell ratio according to the manufacturer's instructions for $48 \mathrm{~h}$. After $48 \mathrm{~h}$, Dynabeads were removed before subsequent experimentation.

Microarray. Gene expression analysis was conducted using Agilent Whole Mouse Genome $4 \times 44$ multiplex format oligo arrays (Agilent Technologies, Englewood, CO, USA) following the Agilent 1-color microarray-based gene expression analysis protocol. Starting with $500 \mathrm{ng}$ of total RNA, Cy3-labeled cRNA was produced according to the manufacturer's protocol. For each sample, $1.65 \mu \mathrm{g}$ of Cy3-labeled cRNAs were fragmented and hybridized for $17 \mathrm{~h}$ in a rotating hybridization oven. Slides were washed and then scanned with an Agilent Scanner. Data were obtained using the Agilent Feature Extraction software (v9.5), using the 1-color defaults for all parameters. The Agilent Feature Extraction Software performed error modeling, adjusting for additive and multiplicative noise. The resulting data were processed using the Rosetta Resolver system (version 7.2; Rosetta Biosoftware, Kirkland, WA, USA). Principal component analysis was performed on all samples and all probes to characterize the variability present in the data. Differentially expressed probes were identified using analysis of variance (ANOVA) to determine if there was a statistical difference between the means of groups. The number of false positives was reduced using a multiple test correction. Specifically, an error-weighted ANOVA and Benjamini-Hochberg multiple test correction with a $P$-value of $<0.0$ were performed with Rosetta Resolver (Rosetta Biosoftware). Significantly regulated genes were analyzed using IPA (Ingenuity Systems, Redwood City, CA, USA). The microarray data discussed in this manuscript have been deposited in the NCBl's Gene Expression Omnibus (GEO, http://www.ncbi.nlm.nih.gov/geo/) and are accessible through GEO accession no. GSE62531.

Statistics. One-way ANOVA followed by Tukey's multiple comparison tests or paired $t$-tests were used to evaluate the statistical relevance of control and experimental samples. A $P$-value of at least $<0.05$ was considered significant.

\section{Conflict of Interest}

The authors declare no conflict of interest.

Acknowledgements. We thank Laura Wharey and Kevin Gerrish of the National Institute of Environmental Health Sciences microarray facility for the generation and initial analysis of the microarray data and Dr Karen Debalsi for her helpful discussion on the Seahorse Technology. This research was supported by the Intramural Research Program of the NIH, National Institute of Environmental Health Sciences.

1. Topham CH, Taylor SS. Mitosis and apoptosis: how is the balance set? Curr Opin Cell Biol 2013; 25: 780-785.

2. Kerr JF, Wyllie AH, Currie AR. Apoptosis: a basic biological phenomenon with wide-ranging implications in tissue kinetics. Br J Cancer 1972; 26: 239-257.

3. McConkey DJ. Biochemical determinants of apoptosis and necrosis. Toxicol Lett 1998; 99: 157-168.

4. Chowdhury I, Tharaken B, Bhat GK. Current concepts in apoptosis: the physiological suicide program revisited. Cell Mol Biol Lett 2006; 11: 506-525.

5. Favaloro B, Allocati N, Graziano V, Di llio C, De Laurenzi V. Role of apoptosis in disease. Aging 2012; 4: 330-349.

6. Ouyang L, Shi Z, Zhao S, Wang FT, Zhou TT, Liu B et al. Programmed cell death pathways in cancer: a review of apoptosis, autophagy and programmed necrosis. Cell Prolif 2012; 45: 487-498.

7. Sessler T, Healy S, Samali A, Szegezdi E. Structural determinants of DISC function: new insights into death receptor-mediated apoptotic signaling. Phamacol Ther 2013; 140: 186-199.

8. Schneider-Brachert W, Heigl U, Ehrenschwender M. Membrane trafficking of death receptors: implications on signaling. Int J Mol Sci 2013; 14: 14475-14503.

9. Trauth BC, Klas C, Peters AM, Matzku S, Moeller P, Falk W et al. Monoclonal antibodymediated tumor regressions by induction of apoptosis. Science 1989; 245: 301-305.
10. Itoh N, Yonehara S, Ishil A, Yonehara M, Mizushima S, Sameshima M et al. The polypeptide encoded by the cDNA for human cell surface antigen Fas can mediate apoptosis. Cell 1991; 66: 233-243.

11. Nagata S. Apoptosis by death factor. Cell 1997; 88: 355-365.

12. Schulze-Osthoff K, Ferrari D, Los M, Wesselborg S, Peter ME. Apoptosis signal by death receptors. Eur J Biochem 1998; 254: 439-459.

13. Kischkel FC, Hellbardt S, Behrmann I, Germer M, Pawlita M, Krammer PH et al. Cytotoxicitydependent APO-1 (Fas/CD95)-associated proteins form a death-inducing signaling complex (DISC) with the receptor. EMBO J 1995; 14: 5579-5588.

14. Guicciardi ME, Gores GJ. Life and death by death receptors. FASEB J 2009; 23 1625-1637.

15. Fulda S, Debatin KM. Extrinsic versus intrinsic apoptosis pathways in anticancer chemotherapy. Oncogene 2006; 25: 4798-4811.

16. Green DR, Kroemer G. The pathophysiology of mitochondrial cell death. Science 2004; 305 626-629.

17. Saelens X, Festjens N, Vande Walle L, van Gurp M, van Loo G, Vanderabeele P. Toxic proteins released from mitochondria in cell death. Oncogene 2004; 23: 2861-2874.

18. Cain K, Bratton SB, Langlais C, Walker G, Brown DG, Sun XM et al. Apaf-1 oligomerizes into biologically active approximately $700-\mathrm{kDa}$ and inactive approximately $1.4-\mathrm{mDz}$ apoptosome complexes. J Biol Chem 2000; 275: 6067-6070.

19. Du C, Fang M, Li Y, Li L, Wang X. Smac, a mitochondrial protein that promotes cytochrome c-dependent caspase activation by eliminating IAP inhibition. Cell 2000; 102: 33-42.

20. Suzuki Y, Imai $Y$, Nakayama H, Takahashi K, Takio K, Takahashi R. A serine protease, HtrA2, is released from the mitochondria and interacts with XIAP, inducing cell death. Mol Cell 2001; 8: 613-621.

21. Moldoveanu T, Follis AV, Kriwacki RW, Green DR. Many players in BCL-2 family affairs. Trends Biochem Sci 2014; 39: 101-111.

22. Youle RJ, Strasser A. The BCL-2 protein family: opposing activities that mediate cell death. Nat Rev Mol Cell Biol 2008; 9: 47-59.

23. Indran IR, Tufo G, Pervaiz S, Brenner C. Recent advances in apoptosis, mitochondria and drug resistance in cancer cells. Biochem Biophys Acta 2011; 1807: 735-745.

24. Bortner CD, Cidlowski JA. Cellular mechanisms for the repression of apoptosis. Annu Rev Pharmocol Toxicol 2002; 42: 259-281.

25. Hoffmann EK, Lambert IH, Pederson SF. Physiology of cell volume regulation in vertebrates. Physiol Rev 2009; 89: 193-277.

26. Lang $\mathrm{F}$, Hoffmann EK. Role of ion transport in control of apoptotic cell death. Compr Physiol 2012; 3: 2037-2061.

27. Green DR, Galluzzi L, Kroemer G. Metabolic control of cell death. Science 2014; 345 : 1250256.

28. Bortner CD, Scoltock AB, Sifre MI, Cidlowski JA. Osmotic stress resistance imparts acquired anti-apoptotic mechanisms in lymphocytes. J Biol Chem 2012; 287: 6284-6295.

29. Perl M, Denk S, Kalbitz M, Huber-Lang M. Granzyme B: a new crossroad of complement and apoptosis. Adv Exp Med Biol 2012; 946: 135-146.

30. Emberley ED, Murphy LC, Watson PH. S100 proteins and their influence on pro-survival pathways in cancer. Biochem Cell Biol 2004; 82: 508-515.

31. Yu J, Berga SL, Zou W, Sun HY, Johnston-MacAnanny E, Yalcinkaya T et al. Gap junction blockade induces apoptosis in human endometrial stromal cells. Mol Reprod Dev 2014; 81: 666-675.

32. Williams RT, Sherr CJ. The INK4-ARF (CDKN2A/B) locus in hematopoiesis and BCR-ABLinduced leukemias. Cold Spring Harb Symp Quant Biol 2008; 73: 461-467.

33. Rethi B, Sammicheli S, Amu S, Pensieroso S, Hejdeman B, Schepis D et al. Concerted effect of lymphopenia, viraemia and T-cell activation on Fas expression of peripheral $B$ cells in HIV-1-infected patients. AIDS 2013; 27: 155-162.

34. Mourtada-Maarabouni M, Watson D, Munir M, Farzaneh F, Williams GT. Apoptosis suppression by candidate oncogene PLAC8 is reversed in other cell types. Curr Cancer Drug Targets 2013; 13: 80-91.

35. Yin F, Liu X, Li D, Wang Q, Zhang W, Li L. Tumor suppressor genes associated with drug resistance in ovarian cancer (review). Oncol Rep 2013; 30: 3-10.

36. Lee H, Lee H, Chin H, Kim K, Lee D. ERBB3 knockdown induces cell cycle arrest and activation of Bak and Bax-dependent apoptosis in colon cancer cells. Oncotarget 2014; 5 5138-5152.

37. Jeelall $Y S$, Wang JQ, Law HD, Domaschenz $H$, Fung HK, Kallies $A$ et al. Human lymphoma mutations reveal CARD11 as the switch between self-antigen-induced B cell death or proliferation and autoantibody production. J Exp Med 2012; 209: 1907-1917.

38. Aguer C, Gambarotta D, Mailloux RJ, Moffat C, Dent R, McPherson R et al. Galactose enhances oxidative metabolism and reveals mitochondrial dysfunction in human primary muscle cells. PLoS One 2011; 6: e28536.

39. Bortner CD, Cidlowski JA. Absence of volume regulatory mechanisms contributes to the rapid activation of apoptosis in thymocytes. Am J Physiol 1996; 271: C950-C961.

40. Lunt SY, Vander Heiden MG. Aerobic glycolysis: meeting the metabolic requirements of cell proliferation. Annu Rev Cell Dev Biol 2011; 27: 441-464.

41. Marko AJ, Miller RA, Kelman A, Frauwirth KA. Induction of glucose metabolism in stimulated T lymphocytes is regulated by mitogen-activated protein kinase signaling. PLoS One 2010; 5: e15425.

42. Frauwirth KA, Riley JL, Harris MH, Parry RV, Rathmell JC, Plas DR et al. The CD28 signaling patahway regulates glucose metabolism. Immmunity 2002; 16: 769-777. 
43. Fox CJ, Hammerman PS, Thompson CB. Fuel feeds function: energy metabolism and the T-cell response. Nat Rev Immunol 2005; 5: 844-852.

44. Dhup S, Dadhich RK, Porporato PE, Sonveaux P. Multiple biological activities of lactic acid in cancer: influences on tumor growth, angiogenesis and metastasis. Curr Pharm Des 2012; 18: $1319-1330$.
45. Stanley IA, Ribeiro SM, Gimenez-Cassina A, Norberg E, Daniel NN. Changing appetites: the adaptive advantages of fuel choice. Trends Cell Biol 2014; 24: 118-127.

46. Harper ME, Antoniou A, Villalobos-Menuey E, Russo A, Trauger R, Vendemelio M et al. Characterization of a novel metabolic strategy used by drug-resistant tumor cells. FASEB J 2002; 16: 1550-1557.

Supplementary Information accompanies this paper on Cell Death and Differentiation website (http://www.nature.com/cdd) 